\title{
DOES PROLONGED CHEMOTHERAPY RESULT IN LOSS OF IMMUNITY IN PREVIOSULY VACCINATED CHILDREN WITH ACUTE LYMPHOBLASTIC LEUKEMIA" A RETROSPECTIVE ANALYSIS OF PATIENTS TREATED AT OLCHC $2006-2016$
}

E.Brennan ${ }^{1}$. A.O.Riordan ${ }^{2}$ L.Storey ${ }^{3}$ A.Malone ${ }^{4}$. O.Smith ${ }^{5}$. A.O.Marcaigh ${ }^{6}$.

Department of Haematology, Our Lady's Children's Hospital Crumlin.

Royal College Of Surgeons in Ireland.

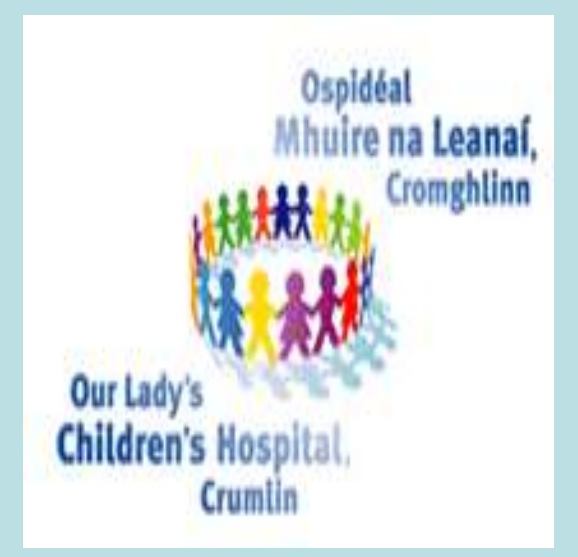

\section{Background}

Currently the cure rate for children diagnosed with acute lymphoblastic leukaemia (ALL) in Ireland is over $90 \%{ }^{1}$. Advances in chemotherapy treatment protocols have resulted in a large cohort of long term survivors. However, despite this progress, one of the well-established side effects of chemotherapy for treatment of ALL is impaired humoral and cellular immunity, leading to significant immunodeficiency.

\section{Objective}

To assess the presence of protective antibodies to measles, mumps and rubella virus pre- and post- chemotherapy in Irish children treated for ALL and to identify possible factors that might predict loss of immunity such as intensity of chemotherapy regimen, age, and the gender.

\section{Method}

A descriptive, cross sectional, retrospective analysis, single centred national study was conducted which included all patients diagnosed with ALL, at Our Ladies Children's Hospital Crumlin (OLCHC), Dublin, between the ages of 1 and 16, from April 2006 to April 2016. The study included all patients who received first line treatment as per the UKALL protocol and received the Irish national immunization vaccine protocol.

\section{Table I: Presence of protective titres against measles and age at diagnosis}

\begin{tabular}{llll}
\hline $\begin{array}{l}\text { Age group } \\
\text { (years old) }\end{array}$ & $\begin{array}{l}\text { Total } \\
\text { number of } \\
\text { patients in } \\
\text { age group. }\end{array}$ & $\begin{array}{l}\text { Positive- } \\
\text { positive } \\
\text { patients (54) }\end{array}$ & $\begin{array}{l}\text { Positive-negative } \\
\text { patients (70) }\end{array}$ \\
\hline I-5 & 82 & $36(44 \%)$ & $46(56 \%)$ \\
$6-10$ & 27 & $10(37 \%)$ & $17(63 \%)$ \\
II-16 & 15 & $8(53.3 \%)$ & $7(46.7 \%)$ \\
TOTAL & 124 & $54(44 \%)$ & $70(56 \%)$ \\
\hline
\end{tabular}

Discussion

An overall decrease in vaccine induced immunity to measles, mumps and rubella protective antibodies post-chemotherapy was observed. Both Zengin et $\mathrm{al}^{2}$ and Lehrnbecher $\mathrm{T}^{3}$ et al recommend revaccination 3 months after completion of maintenance chemotherapy. In this study, post-therapy antibody titres were obtained 9 months after cessation of maintenance chemotherapy as this is currently the standard best practice for serology follow up in OLCHC. There is little evidence in the literature regarding the effect of gender, however our results suggest that the increased duration of chemotherapy that males receive may have a negative effect on their protective antibodies against measles virus leading to a greater loss of immunity. This study was limited by small numbers and incomplete follow up, Further studies are needed to investigate these findings.

1: Pui C-H, Yang JJ, Hunger SP, et al. Childhood Acute Lymphoblastic Leukemia: Progress Through Collaboration. Journal of Clinical Oncology. 2015;33(27):2938-2948 doi:10.1200/JCO.2014.59.1636.

2:8. Zengin E, Sarper N. Humoral immunity to diphtheria, tetanus, measles, and hemophilus influenzae type b in children with acute lymphoblastic leukemia and response to revaccination. Pediatr Blood Cancer 2009;53:967-72

3. British journal haematology 2011 152:754-7 Revaccination of children after completion of standard chemotherapy for acute lymphoblastic leukaemia:a pilot study comparing different schedules. Lehrnbecher T, Schubert R, Allwinn R. 